\title{
Use of erythromycin for the treatment of severe chronic constipation in children
}

M.A. Bellomo-Brandão, E.F. Collares and E.A.L. da-Costa-Pinto
Departamento de Pediatria, Faculdade de Ciências Médicas, Universidade Estadual de Campinas, Campinas, SP, Brasil

\section{Correspondence \\ E.A.L. da Costa Pinto \\ Estrada da Rhodia, km 15, 7250 \\ Casa 28, Condomínio Lagoa Serena \\ 13085-850 Campinas, SP \\ Brasil \\ Fax: +55-19-3788-7193 \\ E-mail: elizcostapinto@terra.com.br}

Publication supported by FAPESP.

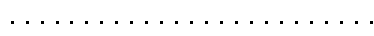

Received December 16, 2002 Accepted May 27, 2003

\begin{abstract}
The efficacy of erythromycin was assessed in the treatment of 14 children aged 4 to 13 years with refractory chronic constipation, and presenting megarectum and fecal impaction. A double-blind, placebocontrolled, crossover study was conducted at the Pediatric Gastroenterology Outpatient Clinic of the University Hospital. The patients were randomized to receive placebo for 4 weeks followed by erythromycin estolate, $20 \mathrm{mg} \mathrm{kg}^{-1} \mathrm{day}^{-1}$, divided into four oral doses for another 4 weeks, or vice versa. Patient outcome was assessed according to a clinical score from 12 (most severe clinical condition) to 0 (complete recovery). At enrollment in the study and on the occasion of follow-up medical visits at two-week intervals, patient score and laxative requirements were recorded. During the first 30 days, the mean $\pm \mathrm{SD}$ clinical score for the erythromycin group $(\mathrm{N}=6)$ decreased from $8.2 \pm 2.3$ to $2.2 \pm 1.0$ while the score for the placebo group $(\mathrm{N}=$ 8) decreased from $7.8 \pm 2.1$ to $2.9 \pm 2.8$. During the second crossover phase, the score for patients on erythromycin ranged from $2.9 \pm 2.8$ to $2.4 \pm 2.1$ and the score for the patients on placebo worsened from 2.2 \pm 1.0 to $4.3 \pm 2.3$. There was a significant improvement in score when patients were on erythromycin $(\mathrm{P}<0.01)$. Mean laxative requirement was lower when patients ingested erythromycin $(\mathrm{P}<0.05)$. No erythromycin-related side effects occurred. Erythromycin was useful in this group of severely constipated children. A larger trial is needed to fully ascertain the prokinetic efficacy of this drug as an adjunct in the treatment of severe constipation in children.
\end{abstract}

Constipated children presenting fecal impaction and soiling show disrupted colonic propulsive motility (1) and are usually refractory to laxative and fiber therapy (2). Few prokinetic drugs have been evaluated in these patients. Cisapride has some effect on constipation (3), but the side effects related to cardiac dysrhythmias have restricted its use (4). Prucalopride, a selective 5-hydroxytryptamine receptor agonist, accelerates co-
Key words

- Gastrointestinal motility

- Constipation

- Children

- Prokinetics

- Erythromycin lonic transit in adults with constipation, but has not yet been tested in children (5).

Erythromycin is a prokinetic agent that acts via motilin receptors on cholinergic neurons and on smooth muscle cells present in the human gastrointestinal system (6). A number of studies carried out to investigate the prokinetic action of erythromycin in children (7) have obtained considerable evidence that the drug may be a useful prokinetic 
agent in feeding intolerance associated with prematurity, in low birth weight infants recovering from abdominal surgery, and in older children with a variety of other gastrointestinal disorders (8-11). Only one randomized placebo-controlled trial has been conducted (12) and there are no clinical studies on the use of erythromycin in children with constipation.

The objective of the present study was to assess the efficacy of erythromycin as an adjunct in the treatment of chronic, refractory constipation in children.

A double-blind, placebo-controlled crossover study was conducted at the State University of Campinas Medical School Hospital. Children who attended the Pediatric Gastroenterology Clinic from October 1998 to September 2000 were eligible for the study. The Hospital Ethics Committee approved the study and informed consent was obtained from the parents of all children.

Subjects were randomized to receive placebo or erythromycin first. Erythromycin estolate, $20 \mathrm{mg} \mathrm{kg}^{-1} \mathrm{day}^{-1}$, divided into four doses, was administered orally every $6 \mathrm{~h}$ before meals. The maximum dose used was $1000 \mathrm{mg}$. Follow-up medical visits were scheduled every two weeks. Only patients with a chronic and sometimes lifelong history of constipation were included, considering the following enrollment criteria: 1) stool passage frequency less than three times per week, 2) presence of diurnal and nocturnal soiling, 3) presence of fecal impaction defined as a filled rectum and identified by a palpable abdominal mass or by digital rectal examination, 4) no previous or current disease known to affect gastrointestinal motility, 5) no history of gastrointestinal subocclusive episodes, 6) absence of mechanical obstruction as determined by barium enema, 7) absence of outlet obstruction evaluated by defecography, and 8) presence of rectal anal inhibitory reflex detected by anorectal manometry and a normal balloon expulsion test.
Liver function was evaluated by determining serum transaminase, alkaline phosphatase and gamma-glutamyltransferase activity, before starting medication and at the end of the study.

After the first medical visit, the patient was admitted to the hospital for fecal impaction removal by consecutive enemas. After colonic cleansing, an oral osmotic laxative was prescribed as maintenance therapy to establish a regular frequency of bowel movements. Lactulose $(667 \mathrm{mg} / \mathrm{ml})$ or magnesium hydroxide $(80 \mathrm{mg} / \mathrm{ml})$ was administered at a daily dose of $2 \mathrm{ml} / \mathrm{kg}$, with a maximum dose of $60 \mathrm{ml}$. Parents were instructed to use a saline-glycerol enema when there was no spontaneous stool movement after a 72-h period. Patients were instructed to sit on the toilet for 5 to $10 \mathrm{~min}$ after each meal in order to take advantage of the gastrocolonic response. After the first medical visit the patients returned every 15 days when they were asked about abdominal colic, nausea, vomiting, epigastric pain, diarrhea, jaundice, choluria, skin rash, and symptoms related to bowel movements.

A score scale (Table 1) was used to permit comparison of clinical evaluation data. The score design was based on a validated symptom scoring system for constipated adults (13). An initial score value was obtained just before impaction removal and every 15 days thereafter until the 8 th week of the study. As an example, a child presenting fecal impaction (2 points), soiling (2 points), reporting pain at stool passage occasionally (1 point), scybalous fecal consistency (2 points), and stool frequency less than one per week ( 2 points) received an initial score of 9 . The score scale included the requirement of a laxative. During the study, the initially prescribed laxative dose $\left(2 \mathrm{ml} \mathrm{kg}^{-1}\right.$ day $^{-1}$ ) was maintained, reduced or increased according to stool frequency, fecal consistency and stool passage conditions which occurred during the previous 2 weeks. The laxative dose was reduced when patient men- 
tioned liquid fecal consistency and increased evacuation in the presence of hard/scybalous fecal consistency or a stool frequency of less than 3 per week or enema requirement during the previous period.

Analysis of variance for crossover studies was used to test the null hypothesis of no difference among group means. Laxative requirement was evaluated comparing the mean doses on days 15 and 30 with the mean doses on days 45 and 60 in each group by the Wilcoxon test. A P value of less than 0.05 was taken to be statistically significant.

Twenty-one children fulfilled the inclusion criteria and were enrolled in the trial. Seven were excluded for the following reasons: children refused to take any medication including the laxatives and the test substance $(\mathrm{N}=3)$, failure to return for the scheduled second medical visit $(\mathrm{N}=3)$, and failure to take the four daily doses of the test drug $(N=1)$. Six patients completed the study after taking the erythromycin-to-placebo sequence (group I), and 8 children completed the inverse crossover sequence placebo-to-erythromycin (group II). The clinical features of the patients allocated to the two groups were similar. Mean $( \pm \mathrm{SD})$ age was $9.7 \pm 3.0$ and $9.6 \pm 3.3$ years for group I and group II, respectively. Group I included one girl and group II, two girls. Age at onset of constipation (mean \pm SD) was $5.1 \pm 3.8$ years for group I, and $3.5 \pm 2.6$ years for group II. Duration of constipation (mean \pm $\mathrm{SD)}$ was $4.6 \pm 3.6$ and $5.8 \pm 1.9$ years for group I and group II, respectively.

Patients reported no side effects and did not present laboratory evidence of hepatic toxicity.

The score for the erythromycin group (mean $\pm \mathrm{SD}$ ) decreased from $8.2 \pm 2.3$ to 2.2 \pm 1.0 in the first 30 days, while in the placebo group it decreased from $7.8 \pm 2.1$ to $2.9 \pm$ 2.8 . In the second crossover phase, the score for patients on erythromycin ranged from $2.9 \pm 2.8$ to $2.4 \pm 2.1$ and the score for those on placebo worsened from $2.2 \pm 1.0$ to $4.3 \pm$
2.3. Figure 1 shows that patient outcome was quite similar in the two groups during the first month of the study. In the second crossover phase, mean scores showed a progressive divergence. In patients on erythromycin, mean scores continued to be favorable, whereas they worsened significantly in patients on placebo. Two group I patients presented relapses of fecal impaction in the second crossover phase.

The $\mathrm{P}$ values for the hypothesis tested by analysis of variance for a crossover study were the following: 1) the mean score of group I during the period of erythromycin ingestion was similar to that of group II

\begin{tabular}{|c|c|c|c|c|c|c|}
\hline Value & $\begin{array}{c}\text { Weekly } \\
\text { stool } \\
\text { frequency }\end{array}$ & $\begin{array}{c}\text { Fecal } \\
\text { impaction }\end{array}$ & Soiling & $\begin{array}{c}\text { Pain or } \\
\text { difficulty at } \\
\text { stool passage }\end{array}$ & $\begin{array}{c}\text { Fecal } \\
\text { consistency }\end{array}$ & $\begin{array}{l}\text { Laxative } \\
\text { dose } \\
\left(\mathrm{ml} \mathrm{kg}^{-1} \text { day }^{-1}\right)\end{array}$ \\
\hline 0 & $\geq 3$ & Absent & Absent & Never & $\begin{array}{l}\text { Soft/loose/ } \\
\text { liquid }\end{array}$ & No \\
\hline 1 & $1-2$ & - & - & Occasional & Hard & $<1$ \\
\hline 2 & $<1$ & Present & Present & Often & Scybalous & $1-2$ \\
\hline 3 & - & - & - & Occasional enema & - & $>2$ \\
\hline 4 & - & - & - & $\begin{array}{c}\text { No spontaneous } \\
\text { passage }\end{array}$ & - & - \\
\hline
\end{tabular}

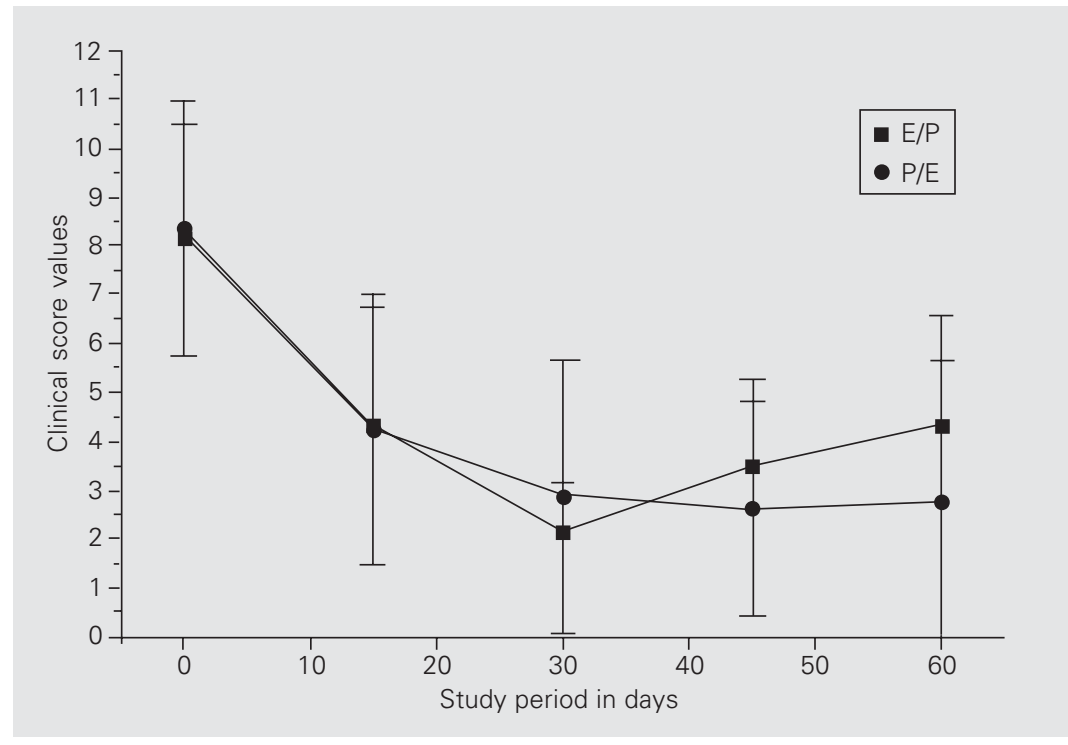

Figure 1. Clinical score outcome. Longitudinal scores (mean $\pm \mathrm{SD}$ ) for group I (erythromycin-to-placebo sequence, E/P, squares), and group II (placebo-to-erythromycin sequence, $\mathrm{P} / \mathrm{E}$, circles) during the crossover study are illustrated. 
during the same period. The groups were also similar during the period of placebo ingestion ( $\mathrm{P}=0.9456) .2$ ) There was no residual drug effect $(\mathrm{P}=0.6973)$ indicating that the sequence of treatment did not interfere with the results and that erythromycin was equally effective when ingested in either 4-week period. 3) The mean scores of the 14 patients during the study (days 0,15 , 30,45 and 60) did not differ significantly (P $=0.0517)$ in the test for treatment versus time interaction. 4) Comparison of the mean scores of the groups in the first and in the second 4-week periods indicated a significant difference $(\mathrm{P}=0.0001)$. Thus, the measures for treating constipation were effective in alleviating the severity of the condition over a 60-day period. 5) Comparison of mean scores for the placebo and erythromycin periods indicated a significant difference, with a lower score being observed during the period of erythromycin ingestion regardless of the sequence of ingestion ( $\mathrm{P}=0.0058)$.

Concerning the laxative requirements, the mean laxative dose during the erythromycin period was lower than during the placebo period $(\mathrm{P}=0.03)$ in group I. Patients in group II required less laxative while taking the prokinetic $(\mathrm{P}=0.01)$.

Animal and clinical studies concerning erythromycin have demonstrated a prokinetic effect of the drug on the gastrointestinal tract at doses lower than those for antibacterial activity, usually less than a quarter of the antibiotic dose. Intravenous administration of $1 \mathrm{mg} / \mathrm{kg}$ induces a migratory motor complex, while higher doses $(7-10 \mathrm{mg} / \mathrm{kg})$ result in sustained contractile activity in the small bowel and suppression of phase III activity (14). Studies on children have tested a wide variety of doses since the optimum dose for a prokinetic activity is not known. Most studies used a 1 - to $3-\mathrm{mg} / \mathrm{kg}$ dose for intravenous administration and a $5-\mathrm{mg} / \mathrm{kg}$ dose by the oral route (7). During the last ten years, about two dozen pediatric clinical trials were conducted, with nine using the oral or en- teral route. Most studies have tested intravenous administration since they included critically ill patients, mainly with gut dysmotility or prematurity. The prokinetic effect is significant when the drug is given orally in the form of ethylsuccinate or estolate, or intravenously as lactobionate. Significantly, no serious adverse effects have been reported in these studies, although fatal ventricular dysrhythmia has followed intravenous administration of antibiotic doses to neonates (15). There are no reports of this complication when erythromycin is given at a prokinetic dose. Hepatotoxicity is a very rare phenomenon in children. It has been reported with the use of erythromycin stearate and ethylsuccinate, and the highest incidence appears to be associated with estolate (16). The hepatic toxic effects usually subside upon withdrawal of erythromycin and long-term liver disease has not been reported.

In the present crossover study, children with chronic refractory constipation experienced a significant relief after fecal impaction removal, regular drug therapy and strict supervision. After the first 4 weeks on therapy, the children showed significantly improved clinical parameters while ingesting erythromycin.

The gastric motor effect of erythromycin has been well established in healthy subjects and in patients with upper gastrointestinal motility dysfunction, but few data are available for the small and large intestine. Studies on healthy adults have indicated an acceleration of intestinal and colonic transit time (17). The identification of motilin receptors in the human colon (18) has stimulated in vitro studies and clinical trials on constipation. Oral erythromycin increased the stool frequency and significantly reduced the total colonic transit time in 11 constipated adults (19). Stenson et al. (11) used erythromycin in food-intolerant preterm infants and, although the drug was not useful in establishing enteral feeding, the patients were prescribed fewer glycerin suppositories for con- 
stipation.

In the current study, the effects of erythromycin were tested during a 60-day period after fecal impaction removal. Conducting the study over this period of time permitted the observation of the effect of erythromycin during a homogeneous stage of therapy among patients. It was hypothesized that to study the prokinetic effect just after impaction removal would be more adequate since it is known that relapses are more probable and frequent during this period of constipation therapy (2). During the second crossover phase the difference between groups became more evident. Erythromycin seems to have been more useful in the second phase when patients on placebo presented worse scores even when using higher doses of laxative. In spite of closer mean scores during the first 30 days of the study, patients on eryth- romycin showed lower laxative requirements than those on placebo. Regular bowel movements and cessation of impaction relapses are considered to be improvement parameters (20). Usually, regular stool passage is established with large doses of laxatives required in the presence of poor propulsive colonic motility. A lower laxative requirement to obtain regular stool passage may indicate a better colonic propulsive competence.

Within the limitations of a small sample, these data indicate the potential importance of erythromycin for alleviating symptoms in children with chronic, severe constipation. More extensive studies should be performed, with lower doses, fewer daily doses or using selective motilin agonists to fully assess the usefulness of erythromycin for treating constipation.

\section{References}

1. Zaslavsky C, da Silveira TR \& Maguilnik I (1998). Total and segmental colonic transit time with radio-opaque markers in adolescents with functional constipation. Journal of Pediatric Gastroenterology and Nutrition, 27: 138-142.

2. Loening-Baucke $V$ (1989). Factors determining outcome in children with chronic constipation and faecal soiling. Gut, 30: 999-1006.

3. Nurko S, Garcia-Aranda JA, Worona LB \& Zlochisty O (2000). Cisapride for the treatment of constipation in children: A doubleblind study. Journal of Pediatrics, 136: 35-40.

4. Mohammad S, Zhou Z, Gong Q \& January CT (1997). Blockage of the HERG human cardiac $\mathrm{K}^{+}$channel by the gastrointestinal prokinetic agent cisapride. American Journal of Physiology, 273: H2534-H2538.

5. Bouras EP, Camilleri M, Burton DD, Thomforde G, McKinzie S \& Zinsmeister AR (2001). Prucalopride accelerates gastrointestinal and colonic transit in patients with constipation without a rectal evacuation disorder. Gastroenterology, 120: 354-360.

6. Coulie B, Tack J, Peeters T \& Janssens J (1998). Involvement of two different pathways in the motor effects of erythromycin on the gastric antrum in humans. Gut, 43: 395-400.

7. Curry JI, Lander TD \& Stringer MD (2001). Review article: erythromycin as a prokinetic agent in infants and children. Alimentary Pharmacology and Therapeutics, 15: 595-603.

8. Costalos C, Gounaris A, Varhalama E, Kokori F, Alexiou N \& Kolovou E (2002). Erythromycin as a prokinetic agent in preterm infants. Journal of Pediatric Gastroenterology and Nutrition, 34: 23-25.

9. Di Lorenzo C, Flores AF, Tomomasa T \& Hyman PE (1994). Effect of erythromycin on antroduodenal motility in children with chronic functional gastrointestinal symptoms. Digestive Diseases and Sciences, 39: 1399-1404.
10. Jadcherla SR \& Berseth CL (2002). Effect of erythromycin on gastroduodenal contractile activity in developing neonates. Journal of Pediatric Gastroenterology and Nutrition, 34: 16-22.

11. Stenson BJ, Middlemist L \& Lyon AJ (1998). Influence of erythromycin on establishment of feeding in preterm infants: observations from a randomised controlled trial. Archives of Disease in Childhood. Fetal and Neonatal Edition, 79: F212-F214.

12. Patole SK, Almonte R, Kadalraja R, Tuladhar R, Muller R \& Whitehall JS (2000). Can prophylactic oral erythromycin reduce time to full enteral feeds in preterm neonates? International Journal of Clinical Practice, 54: 504-508.

13. Knowles $\mathrm{CH}$, Eccersley AJ, Scott SM, Walker SM, Reeves B \& Lunnis PJ (2000). Linear discriminant analysis of symptoms in patients with chronic constipation: validation of a new scoring system. Diseases of the Colon and Rectum, 43: 1419-1426.

14. Otterson MF \& Sarna SK (1990). Gastrointestinal motor effects of erythromycin. American Journal of Physiology, 249: G355-G363.

15. Brandriss MW, Richardson WS \& Barold SS (1994). Erythromycininduced QT prolongation and polymorphic ventricular tachycardia (torsades de pointes): case report and review. Clinical Infectious Diseases, 18: 995-998.

16. Westphal JF, Vetter D \& Brogard JM (1994). Hepatic side effects of antibiotics. Journal of Antimicrobial Chemotherapy, 33: 387-401.

17. Landry C, Vidon N, Sogni P, Nepveux P, Chaumeil JC, Chauvin JP \& Couturier D (1995). Effects of erythromycin on gastric emptying, duodeno-caecal transit time, gastric and biliopancreatic secretion during continuous gastric infusion of a liquid diet in healthy volunteers. European Journal of Gastroenterology and Hepatology, 7: 797-802.

18. Feighner SD, Tan CP, McKee KK et al. (1999). Receptor for motilin 
identified in the human gastrointestinal system. Science, 284: 21842188.

19. Sharma SS, Bhargava N \& Mathur SC (1995). Effect of oral erythromycin on colonic transit in patients with idiopathic constipation. A pilot study. Digestive Diseases and Sciences, 40: 2446-2449.

20. Loening-Baucke VA (1987). Factors responsible for persistence of childhood constipation. Journal of Pediatric Gastroenterology and Nutrition, 6: 15-22. 